\title{
Lacunas de Competências de Egressos do Curso Psicologia na Visão dos Docentes
}

\author{
Rômulo Travassos \\ Universidade Estadual do Maranhão, MA, Brasil.
}

\author{
Luciana Mourão \\ Universidade Salgado de Oliveira, RJ, Brasil.
}

\begin{abstract}
Resumo: Pesquisas sobre a formação do(a) psicólogo(a) brasileiro(a) apontam para resultados preocupantes. Este estudo aborda a importância e o domínio de competências dos egressos dos cursos de Psicologia na visão de coordenadores e docentes de instituições de ensino superior públicas e privadas. Foi realizada análise de dados secundários de projetos pedagógicos de 36 cursos de Psicologia e um survey com 114 docentes distribuídos pelo território nacional, sendo 40 coordenadores de curso. O questionário foi elaborado a partir das diretrizes curriculares para a graduação em Psicologia e continha questões abertas e fechadas. Os resultados apontaram para um reconhecimento da importância das competências na formação em Psicologia. As maiores lacunas da formação referem-se às competências relativas à intervenção em processos psicológicos grupais e organizacionais, e conhecimento habilidades de pesquisa científica, sendo que os coordenadores apresentam uma visão menos crítica que os demais docentes. As respostas às perguntas abertas indicaram pluralidade de opiniões acerca da formação em Psicologia. Conclui-se que há necessidade de maior qualificação do profissional, confirmando achados anteriores e chamando atenção à nova face do perfil de psicólogo(a) no cenário social atual. São apontadas reflexões para estudantes, docentes, profissionais e demais interessados na área.
\end{abstract}

Palavras-chave: Competências, Formação Profissional, Psicologia.

\section{Gaps in the Skills of Graduates of the Psychology Course in the Professors' View}

Abstract: Studies on the professional training of Brazilian psychologists point to worrying results. This study deals with the importance and mastery of competencies, regarding graduates from academic programs in Psychology from the viewpoint of coordinators and professors at public and private higher education institutions. Secondary data from pedagogical projects of 36 Psychology programs was analyzed and a survey was conducted with 114 professors scattered about the country, 40 of which were program coordinators. The questionnaire was based on the undergraduate curricular guidelines for a degree in Psychology, and contained open and closed questions. The results pointed to the recognition of the importance of competencies in academic training in Psychology. The major gaps in the training pertain to the competencies related to intervention in group and organizational psychology processes, and knowledge and skills in scientific research. The coordinators presented a less critical view than the other professors. The answers to the open questions indicated a plurality of opinions about training in Psychology. We concluded that there is a need for higher professional qualification, confirming previous findings and drawing attention to the new aspect of the psychologist's profile in the current social scenario. Reflections are offered for students, professors, professionals, and other stakeholders.

Keywords: Competencies, Professional Training, Psychology. 


\title{
Carencias en las Competencias de los Egresados del Curso de Psicología en la Visión de los Docentes
}

\begin{abstract}
Resumen: Las investigaciones sobre la formación del psicólogo (a) brasileño (a) apuntan hacia resultados preocupantes. Este estudio aborda la importancia y el dominio de competencias de los egresados de los cursos de Psicología en la visión de coordinadores y docentes de instituciones de enseñanza superior públicas y privadas. Se realizó análisis de datos secundarios de proyectos pedagógicos de 36 cursos de Psicología y un survey con 114 docentes distribuidos por el territorio nacional, siendo 40 coordinadores de curso. El cuestionario se elaboró a partir de las directrices curriculares para la graduación en Psicología y contenía cuestiones abiertas y cerradas. Los resultados señalaron el reconocimiento de la importancia de las competencias en la formación en Psicología. Las mayores carencias de la formación se refieren a las competencias relativas a la intervención en procesos psicológicos grupales y organizativos y conocimiento y habilidades de la investigación científica, siendo que los coordinadores presentan una visión menos crítica comparados a los demás docentes. Las respuestas a las preguntas abiertas indicaron pluralidad de opiniones sobre la formación en Psicología. Se concluye que existe la necesidad que el profesional tenga mayor calificación, confirmando hallazgos anteriores y llamando la atención para la nueva cara del perfil de psicólogo en el escenario social actual. Se apuntan reflexiones para los estudiantes, docentes, profesionales y los demás interesados en el área.
\end{abstract}

Palabras clave: Competencias, Formación Profesional, Psicología.

\section{Introdução}

A regulamentação da profissão de psicólogo(a) no Brasil ocorreu em 1962, com um contínuo crescimento do número de profissionais, em um ritmo acelerado na década de 1980 (Antunes, 2012; Vilela, 2012) e também no início do século XXI (Bastos, Gondim, \& Borges-Andrade, 2010). O quantitativo de profissionais inscrito nos Conselhos Regionais de Psicologia concentra-se, sobretudo, na região Sudeste, embora nos últimos anos tenha havido um crescimento da profissão no país como um todo e um processo de interiorização do curso (Bastos et al., 2010).

Essa expansão dos cursos no interior está associada sobretudo à evolução das políticas sociais no Brasil pós-1985, que enfatizaram o processo de inclusão desses profissionais na área social (Yamamoto, \& Oliveira, 2010). Nesse sentido, o alcance social da profissão tem se expandido, ampliando as chances de os(as) psicólogos(as) contribuírem para o processo de transformação social do país (Yamamoto, 2012). Essa evolução das políticas sociais explica a inclusão profissional dos(as) psicólogos(as) predominantemente no setor público $(40 \%)$, embora as fatias dos setores privado (35\%) e o terceiro setor (25\%) também apresentem índices expressivos (Lisboa, \& Barbosa, 2009).
Observa-se que triplicaram o número de Instituições de Ensino Superior (IES) que oferecem o curso de Psicologia, até o ano de 2016, contando com 512 instituições, sendo 434 privadas e 78 públicas - algumas delas ofertando mais de um curso em Psicologia, seja em horários distintos, seja em campi diversificados. Assim, os dados do Censo da Educação Superior 2016, realizado pelo Instituto Nacional de Estudos e Pesquisas Educacionais Anísio Teixeira (INEP), apontam um total de 236.665 matrículas, sendo apenas 11,6\% na rede pública e todo o restante em IES particulares. Desse total, a formação de professor de Psicologia responde por 1.071 matrículas, sendo $52,8 \%$ da rede pública (INEP, 2017a). Essa expansão da oferta de cursos teve também uma clara diversificação territorial e um processo de interiorização (Bastos et al., 2010), a qual se requer uma análise de em que medida há identidade e qualidade na formação dos(as) psicólogos(as).

Diante desse contexto, Yamamoto (2012) discute o alcance, a responsabilidade e o compromisso social da profissão, e apresenta reflexões acerca da viabilidade da proposição de um projeto ético-político para a Psicologia. Para o autor, não se concebe uma ação profissional sem a devida qualificação técnica, embora a competência técnica não represente em si mesma uma 
condição suficiente. Nesse sentido, propõe-se a superação do nível de ação profissional individual, a partir da discussão de um projeto para a profissão, que seja crítico e progressista, construído por um sujeito coletivo, visando atingir toda a categoria profissional.

Obviamente a construção de um projeto ético-político para a profissão deve levar em conta a história da Psicologia em relação ao seu ensino no Brasil, que está relacionada aos fatos históricos mais significativos ocorridos no País (Vilela, 2012). Certamente, as fases da história pelas quais passaram as sociedades influenciaram a evolução dos saberes psicológicos e a institucionalização da profissão. A profissionalização da Psicologia no Brasil aconteceu em três fases, sendo: (i) Fase 1 - Pré-profissional (1833-1890): em que não havia uma sistematização do saber psicológico e a profissão não era regulamentada, mas houve a criação das Faculdades de Medicina do Rio de Janeiro e da Bahia em 1833; (ii) Fase 2 - Profissionalização (1890-1975): caracterizada pela gênese da institucionalização da prática psicológica até a sua regulamentação e o estabelecimento de seus dispositivos formais; e (iii) Fase 3 - Profissional (1975): representa a profissão organizada e estabelecida como tal, marcada por profundas mudanças socioeconômicas, pela proliferação de faculdades de Psicologia e pela desvalorização dessa mão de obra, em decorrência do crescente número de profissionais no mercado do trabalho (Pereira, \& Pereira Neto, 2003; Vilela, 2012).

$\mathrm{Na}$ esteira desse processo de evolução histórica da profissão, em 2011, foi construída uma nova regulamentação para a graduação em Psicologia, concretizada pela Resolução no 5 (de 15 de março de 2011), que instituiu as Diretrizes Curriculares Nacionais (DCNs). As principais inovações dessa nova regulamentação foram: (i) conformação do currículo em um núcleo comum voltado para a capacitação básica dos alunos, e em ênfases curriculares para aprofundamento em algum domínio da Psicologia, com a exigência de oferta mínima de duas opções para escolha do discente; (ii) foco no desenvolvimento de competências agregadas aos conhecimentos; e (iii) ampliação da presença do estágio na formação - no núcleo comum e nas partes específicas (Costa et al., 2012).

Tais medidas pretenderam tornar os cursos mais flexíveis e adaptáveis às transformações sociais, ou seja, às exigências do mercado de trabalho, a fim de dar resposta às demandas de qualificação (Bernardes, 2004). Ao contrário do ocorrido com a Psicologia, muitos processos de reformas curriculares limitam-se à abordagem de conteúdos e disciplinas (Bernardes, 2012), sem uma consequência mais expressiva na formação profissional. Mas embora haja o que comemorar nesses mais de 50 anos de regulamentação da profissão, inclusive em termos da evolução do que foi o primeiro currículo nacional para os cursos de Psicologia, a formação nesse campo ainda requer muitos avanços para que se alcancem os objetivos pretendidos no exercício da profissão de psicólogo(a) (Bernardes, 2004).

Nessa linha, Abbad e Mourão (2010) ponderam que o alto grau de complexidade das competências características do(a) psicólogo(a) contemporâneo(a), refletidas nas Diretrizes Curriculares após a reforma, não produziu ainda mudanças significativas na formação do(a) psicólogo(a) brasileiro(a). As autoras destacam alguns problemas relativos à formação, tais como: poucos professores qualificados para conduzir ensino e pesquisa; currículos desatualizados; poucas oportunidades de estágio; estágios em áreas que exigem práticas tradicionais; poucas oportunidades de intervenção durante o curso; dificuldade de articular as diversas áreas da Psicologia e de estabelecer interfaces com disciplinas de campos afins.

As competências oriundas das Diretrizes Curriculares dos Cursos de Psicologia referem-se a desempenhos e atuações que buscam assegurar ao profissional, um domínio básico de saberes psicológicos e capacidade para aplicá-los em distintos contextos que requerem investigação, análise, avaliação, prevenção e atuação em processos psicológicos e psicossociais, e na promoção da qualidade de vida (Abbad, \& Mourão, 2010). Dessa forma, a formação em Psicologia organiza-se em torno de seis eixos estruturantes, assim especificados: (i) Fundamentos epistemológicos e Históricos; (ii) Fundamentos teórico-metodológicos; (iii) Procedimentos para a investigação científica e a prática profissional; (iv) Fenômenos e processos psicológicos; (v) Interfaces com campos afins do conhecimento; e (vi) Práticas profissionais para atuação em diferentes contextos (Abbad, \& Mourão, 2010).

Em uma linha semelhante, Cruz e Schultz (2009); Brasileiro e Souza (2010) analisam algumas categorias de competências que seriam esperadas dos(as) psicólogos(as), a saber: análise do contexto e do campo de atuação; intervenção e atuação profissional; investigação científica; atuação inter e multiprofissional; e avaliação. Cada uma dessas categorias, segundo os autores, tem características e estratégias de desenvolvimento distintas. 
As análises do contexto e do campo de atuação têm natureza essencialmente cognitiva e incluem capacidades complexas como: predizer, explicar, prever, diagnosticar, prognosticar, emitir julgamentos de valor, estimar, levando em conta diferentes níveis de análise e variáveis (Cruz, \& Schultz, 2009). É uma categoria de grande relevância tendo em vista a importância do contexto para a aprendizagem humana (Abbad, $\&$ Borges-Andrade, 2014).

A intervenção e a atuação profissional, por sua vez, incluem competências cognitivas e atitudinais que servem como elementos integradores de conhecimentos filosóficos, teóricos, metodológicos e éticos. Envolvem avaliações de contextos, campos de atuação e estado da arte nas pesquisas da área específica de atuação, assim como a escolha de intervenções psicológicas adequadas aos fenômenos, processos, população-alvo e contexto. Exigem o desenvolvimento de habilidades de trabalho em equipes inter- e multiprofissionais, com desenvolvimento de habilidades de comunicação oral e escrita, e de análise crítica de teorias, métodos de pesquisa e formas de atuação de disciplinas afins (Cruz, \& Schultz, 2009).

Já a investigação científica tem natureza predominantemente cognitiva e de alta complexidade. Compreende conhecimentos sobre bases filosóficas, epistemológicas, teóricas, metodológicas e éticas, relacionados ao campo de atuação. Envolve decisões complexas sobre a adequação de métodos, técnicas e estratégias de pesquisas ao contexto e ao fenômeno focalizado. De acordo com Cruz e Schultz (2009), integra habilidades de comunicação escrita e oral, bem como conhecimento de normas científicas de publicação e divulgação de pesquisas, além de exigir contato com estudos teóricos e empíricos, e um desenvolvimento de atitudes favoráveis à aprendizagem contínua. O desenvolvimento de competências de investigação científica deve ampliar, portanto, a capacidade de análise, com estratégias cognitivas e metacognitivas de aprendizagem, autoinstrução, autoavaliação, entre outras (Abbad, \& Mourão, 2010).

A atuação inter- e multiprofissional prevê competências igualmente complexas que envolvem múltiplas habilidades, atitudes e conhecimentos. Demanda uma capacidade de trabalho em grupo e em equipes inter- e multiprofissionais, e seu desenvolvimento requer ações educacionais contínuas e integradas com situações propícias à aprendizagem. A participação ativa do aprendiz no processo de construção do seu próprio perfil profissional e seu contato frequente com outras pessoas devem ser uma tônica da formação que busca competências inter- e multiprofissionais (Cruz, \& Schultz, 2009).

Por fim, as competências de avaliação envolvem decisões complexas sobre a adequação de métodos, técnicas e estratégias de pesquisas ao contexto e ao fenômeno focalizado, bem como capacidade de análise, síntese e avaliação. O desenvolvimento desse tipo de competência deve estar baseado em uma formação voltada para a diversificação de métodos e estratégias, e para a criação de situações de aprendizagem que levem o aluno a demonstrar capacidade de análise e julgamento (Abbad, \& Mourão, 2010).

A análise dos eixos estruturantes das diretrizes curriculares do Ministério da Educação (MEC) para o curso de Psicologia e das principais competências definidas para a formação no Brasil aponta, portanto, para um espectro de formação amplo e complexo (Brasileiro, \& Souza, 2010; Cruz, \& Schultz, 2009). Nesse sentido, os problemas da formação do(a) psicólogo(a) em nosso país não parecem estar associados a uma indefinição normativa ou de diretrizes curriculares. De fato, o Conselho Nacional de Educação em conjunto com a Câmara de Educação Superior têm editado, desde 1997, vários pareceres para orientar a elaboração de Diretrizes Curriculares dos Cursos de Graduação, inseridas no rol das ações realizadas pelo MEC, com a finalidade de estabelecer normas disciplinadoras da estrutura e do funcionamento dos cursos de nível superior no Brasil (Souza, Bastos, \& Barbosa, 2011).

No caso da Psicologia, as atuais Diretrizes Curriculares foram aprovadas no ano de 2011 (Resolução No 5, 2011), devendo, a partir de então, os cursos de Graduação em Psicologia basearem-se nelas para a realização de seus projetos de curso. De acordo com tais normas, os cursos devem levar em consideração os aspectos relacionados ao perfil profissional do(a) psicólogo(a), descrito conforme o conjunto de competências e habilidades que caracterizam o eixo comum da formação em Psicologia (Souza et al., 2011).

As diretrizes devem assegurar, portanto, uma identidade para a formação e capacitação básica em Psicologia, como área de conhecimento e de atuação profissional (Souza et al., 2011). As DCNs para a área de Psicologia preveem que a formação atenda aos pré-requisitos da atuação profissional, da pesquisa e ensino de Psicologia, garantindo princípios que podem ser resumidos da seguinte forma: construção e desenvol- 
vimento do conhecimento na área; compreensão dos múltiplos referenciais; reconhecimento da diversidade de perspectivas necessárias para compreensão do ser humano e incentivo à interlocução com outros campos de conhecimento; compreensão crítica dos fenômenos fundamentais ao exercício da cidadania e da profissão; atuação em diferentes contextos que contribuam para a qualidade de vida; respeito à ética; e aprimoramento contínuo (Resolução No 5, 2011).

De acordo com esses princípios, os cursos assumem um compromisso de garantir uma formação ampla do(a) psicólogo(a), respeitando a multiplicidade de suas concepções teóricas e metodológicas, originadas em diferentes paradigmas e modos distintos de compreender a ciência, assim como a diversidade de suas práticas e contextos de atuação (Bastos, Gondim, Souza, \& Souza, 2011). Assim é que, para assegurar uma formação básica comum a todos os cursos de Psicologia nas diferentes regiões e contextos, criou-se um núcleo de competências que se reportam a desempenhos e atuações iniciais requeridas do formando em Psicologia. O estabelecimento desse núcleo comum à formação visa garantir ao profissional, o domínio de conhecimentos psicológicos e a capacidade de utilizá-los em diferentes contextos os quais demandam a investigação, análise, avaliação, prevenção e intervenção em processos psicológicos (Souza et al., 2011).

A despeito desses esforços em termos de repensar a formação em Psicologia, uma análise dos resultados do Enade (Exame Nacional de Desempenho dos Estudantes) indica que a formação do(a) psicólogo(a) ainda apresenta muitas lacunas. Considerando que as questões do Enade se baseiam em uma operacionalização das diretrizes curriculares de cada área (Primi, Hutz, \& Silva, 2011), seria de se esperar resultados positivos da reforma curricular, espelhados nos resultados do Exame. Mas ao contrário do que seria esperado, os resultados do Enade apontaram que as notas dos concluintes de Psicologia vêm caindo nos últimos anos, tanto no componente de formação geral, quanto no componente de formação específica. Em 2006, os resultados da formação geral atingiram média de 47,2 pontos e caiu para 42,1 pontos em 2012. No componente de formação específica, o decréscimo foi ainda maior, passando de uma média de 52,7 pontos em 2006 para 37,6 em 2012. Esse resultado é bastante preocupante na medida em que sinaliza para graves lacunas no desenvolvimento de competências profissionais nos alunos do curso de Psicologia. Não só os dados do Enade, mas outros estudos baseados nas diretrizes curriculares para o curso de Psicologia também vêm sinalizando para lacunas de competências na formação dos(as) psicólogos(as). Quer seja em pesquisas com egressos (Abbad, \& Mourão, 2010) ou com alunos (Mourão, \& Abbad, 2016), conclui-se que há deficiências de formação em um conjunto de competências. Assim, o presente estudo dá continuidade a esse esforço de avaliar a qualidade da formação em Psicologia, e objetiva identificar a importância atribuída às competências profissionais, bem como o domínio de competências dos egressos a partir da percepção dos coordenadores e docentes dos cursos de Psicologia.

\section{Método}

\section{Participantes}

O presente estudo contou com uma amostra nacional de docentes de cursos de Psicologia, totalizando 114 respondentes, sendo $65,9 \%$ professores, $35,1 \%$ coordenadores, com faixa etária média de 42,3 anos de idade, e tempo médio de atuação na carreira de 8,3 anos. As mulheres responderam por 72,6\% da amostra e a escolaridade predominante foi de doutores $(49,1 \%)$ e mestres $(44,6 \%)$. A maioria dos pesquisados era vinculada ao setor privado $(69,4 \%)$, com predomínio das regiões Sudeste $(49,6 \%)$, Nordeste $(30,1 \%)$ e Sul (16,8\%). As regiões Norte e Centro-Oeste tiveram baixa representatividade na pesquisa $(1,8 \%$, cada).

\section{Instrumentos}

Como instrumento de coleta de dados foi utilizado um questionário com perguntas abertas e fechadas, envolvendo as competências estabelecidas pelo MEC para a formação em Psicologia a partir das escalas de autoavaliação da importância e do domínio de competências de psicólogo(a), conforme escala elaborada por Abbad e Mourão (2010). Os participantes da pesquisa deveriam avaliar, a partir de uma escala de zero a dez, qual a importância de cada uma das 21 competências definidas pelo MEC para a formação em Psicologia, e também o grau de domínio que os concluintes do curso em que lecionam tinham de cada uma das competências listadas. De forma complementar, foram também incluídas questões abertas para aprofundar a avaliação da formação em Psicologia. 


\section{Procedimentos de coleta de dados}

A pesquisa foi previamente inscrita na Plataforma Brasil e aprovada por um comitê de ética em pesquisa. A coleta de dados foi realizada em dois momentos distintos. No primeiro foi feito um levantamento de Projetos Pedagógicos nos sites dos cursos de instituições de ensino públicas e privadas. Nos casos em que o Projeto Pedagógico não estava no site institucional, foi enviado e-mail à coordenação solicitando o envio do referido Projeto. De uma consulta inicial de 80 instituições, obteve-se um total de 36 Projetos Pedagógicos para análise. No segundo momento foi realizado um survey com docentes dos cursos de Psicologia. Nessa coleta foram respeitados o sigilo das informações individuais e o direito à participação e à desistência de continuidade na pesquisa. Todos os indivíduos que aceitaram participar do estudo, assinaram o Termo de Consentimento Livre e Esclarecido. Os questionários foram enviados por e-mail ou entregues pessoalmente a coordenadores e professores do curso de Psicologia de várias regiões do País.

\section{Procedimentos de análise de dados}

A análise dos dados foi predominantemente descritiva, considerando as competências com maiores graus de importância e de domínio. As lacunas foram operacionalmente definidas como o produto da percepção de importância das competências pela percepção de ausência de domínio das mesmas, de modo que, quanto menor o domínio e maior a importância da competência, maior a lacuna identificada.

Os resultados foram avaliados mostrando as médias e os desvios-padrão relativos à importância, domínio e lacunas de competências dos concluintes do curso de Psicologia, na opinião dos docentes. Para fins de comparação entre os dois públicos-alvo e os tipos de IES, foram realizados testes $t$. Nas perguntas abertas, foi feita análise de conteúdo categorial, a partir do agrupamento de elementos de significados mais próximos, com formação de agrupamentos temáticos.

\section{Resultados e discussão}

A análise dos 36 Projetos Pedagógicos mostrou que a carga horária é diversificada. Enquanto alguns cursos atendem ao mínimo especificado pela legislação para a formação em Psicologia (4.000 horas), há cursos com carga horária maior, tendo o número máximo encontrado sido de 5.388 horas. Contudo, algumas IES apresentam o detalhamento de sua carga horária, subdividida em disciplinas obrigatórias, eletivas e optativas, bem como os estágios, enquanto outras disciplinas apresentam a descrição apenas das disciplinas obrigatórias e informam o total de horas a ser cumprido. Assim, observa-se que alguns Projetos Pedagógicos optam por apresentar um número relativamente reduzido de disciplinas obrigatórias e proporcionar maior liberdade de escolha aos discentes, enquanto outros têm uma definição de grade de disciplinas mais restrita.

O número de disciplinas obrigatórias entre os cursos também é bastante variável, de 22 a 60 disciplinas obrigatórias, com média de 37 disciplinas ( $\mathrm{DP}=13$ ). Isso sinaliza que alguns Projetos Pedagógicos foram pensados com um currículo mínimo e buscando dar maior liberdade de escolha ao estudante no processo de formação, enquanto outros definem uma grade de disciplinas obrigatórias muito mais ampla. Os resultados mostram que as universidades públicas tendem a oferecer mais disciplinas eletivas $(\mathrm{M}=10 ; \mathrm{DP}=5,9)$ do que as instituições privadas $(\mathrm{M}=$ 7; DP = 2,4). A expressiva diferença nos Projetos Pedagógicos dos cursos mostra que há baixa padronização do curso de Psicologia, mesmo com a existência do núcleo comum definido para a formação na área.

Na pesquisa feita com os docentes, os resultados relativos à Importância, Domínio e Lacunas de competências foram agrupados em quatro dimensões, conforme a Escala de Importância das Competências apresentada por Abbad e Mourão (2010), a saber: (i) Intervenção em processos psicológicos individuais; (ii) Intervenção em processos psicológicos grupais e organizacionais; (iii) Conhecimentos e habilidades de pesquisa científica; e (iv) Aplicação de habilidades científicas e interação com outros profissionais (Tabela 1). Dentre essas dimensões percebeu-se que a Intervenção em processos psicológicos grupais e organizacionais é a mais crítica, no sentido de ter todos os itens com expressiva lacuna de competências nos concluintes dos cursos de Psicologia.

Na dimensão Intervenção em processos psicológicos individuais identifica-se que a competência em que os formandos em Psicologia estão mais preparados é Realizar psicoterapia, enquanto a competência em que há maior lacuna na formação é Elaborar pareceres técnicos, laudos e comunicações profissionais. Esses resultados confirmam o que foi obtido na pesquisa com psicólogos(as) realizada por Abbad e Mourão (2010), 
Tabela 1

Médias e desvios-padrão da importância, domínio e lacunas de competências dos concluintes dos cursos de Psicologia na avaliação dos docentes $(\mathrm{n}=114)$.

\begin{tabular}{|c|c|c|c|}
\hline \multirow{2}{*}{ Competências requeridas dos(as) psicólogos(as) } & Importância & Domínio & Lacunas \\
\hline & Média (DP) & Média (DP) & Média (DP) \\
\hline \multicolumn{4}{|l|}{ Dimensão: Intervenção em processos psicológicos individuais } \\
\hline Realizar orientação psicológica. & $8,9(1,4)$ & $7,1(1,8)$ & $24,7(15,1)$ \\
\hline Realizar psicoterapia. & $9,0(1,7)$ & $7,3(1,9)$ & $22,7(16,2)$ \\
\hline Realizar aconselhamento psicológico. & $8,7(1,5)$ & $7,1(1,7)$ & $24,5(14,0)$ \\
\hline Realizar diagnósticos de processos psicológicos de indivíduos. & $9,3(1,2)$ & $7,2(1,8)$ & $25,3(16,7)$ \\
\hline $\begin{array}{l}\text { Realizar intervenções de caráter terapêutico, de acordo com as } \\
\text { situações e os problemas específicos. }\end{array}$ & $9,5(1,2)$ & $7,3(1,8)$ & $24,5(16,1)$ \\
\hline Analisar necessidades de natureza psicológica. & $9,5(0,9)$ & $7,3(1,7)$ & $24,6(16,0)$ \\
\hline $\begin{array}{l}\text { Avaliar problemas humanos (de ordem cognitiva, comportamental, } \\
\text { afetiva) em diferentes contextos. }\end{array}$ & $9,6(0,9)$ & $7,4(1,8)$ & $24,6(16,3)$ \\
\hline Elaborar pareceres técnicos, laudos e comunicações profissionais. & $9,6(0,9)$ & $6,7(2,1)$ & $31,0(20,0)$ \\
\hline \multicolumn{4}{|l|}{ Dimensão: Intervenção em processos psicológicos grupais e organizacionais } \\
\hline Realizar diagnósticos de processos psicológicos de grupos. & $9,2(1,0)$ & $6,5(1,9)$ & $30,9(16,6)$ \\
\hline Realizar diagnósticos de processos psicológicos de organizações. & $9,0(1,6)$ & $6,5(2,0)$ & $29,9(17,2)$ \\
\hline Coordenar processos grupais. & $9,2(1,0)$ & $6,8(1,9)$ & $28,8(16,9)$ \\
\hline \multicolumn{4}{|l|}{ Dimensão: Conhecimentos e habilidades de pesquisa científica } \\
\hline Elaborar relatos científicos. & $9,4(1,2)$ & $6,6(2,1)$ & $31,8(18,8)$ \\
\hline Formular questões empíricas de investigação científica. & $9,2(1,1)$ & $6,5(2,2)$ & $32,2(20,4)$ \\
\hline Apresentar trabalhos e discutir ideias em público. & $9,3(1,1)$ & $7,5(1,8)$ & $22,4(16,0)$ \\
\hline Utilizar instrumentos e procedimentos de coleta de dados. & $9,1(1,1)$ & $7,1(1,8)$ & $25,9(16,1)$ \\
\hline Analisar o contexto em que atua profissionalmente. & $9,6(0,8)$ & $7,4(1,8)$ & $24,7(17,0)$ \\
\hline \multicolumn{4}{|c|}{ Dimensão: Aplicação de habilidades científicas e interação com outros profissionais } \\
\hline $\begin{array}{l}\text { Realizar intervenções de caráter preventivo, de acordo com as situações } \\
\text { e os problemas específicos. }\end{array}$ & $9,6(0,8)$ & $6,9(2,0)$ & $29,5(19,2)$ \\
\hline Utilizar conhecimento científico necessário à atuação profissional. & $9,8(0,5)$ & $7,2(1,9)$ & $27,3(19,0)$ \\
\hline Atuar com profissionais de outras áreas, quando recomendável. & $9,5(0,9)$ & $7,4(1,8)$ & $24,9(17,4)$ \\
\hline Gerar conhecimento a partir da prática profissional. & $9,5(1,0)$ & $6,8(2,0)$ & $30,2(19,2)$ \\
\hline Desenvolver vínculos interpessoais requeridos na atuação profissional. & $9,4(1,3)$ & $7,8(1,8)$ & $19,4(14,9)$ \\
\hline
\end{tabular}

Notas.: As competências listadas referem-se às 21 definidas pelo Ministério da Educação como essenciais para a atuação em Psicologia, agrupadas em quatro dimensões, conforme Abbad e Mourão (2010). A importância e o domínio dos alunos concluintes nessas competências foram avaliadas pelos docentes em uma escala de zero a dez. A lacuna de competência foi calculada multiplicando-se o valor atribuído à importância pelo gap de domínio percebido (ou seja, o valor de domínio atribuído pelo docente, subtraído do valor máximo da escala - que no caso é 10).

sinalizando que o problema não ocorre apenas durante a formação, mas se perdura na vida profissional.

Em Intervenção em processos psicológicos grupais e organizacionais, os três itens (Realizar diag- nósticos de processos psicológicos de grupos; Realizar diagnósticos de processos psicológicos de organizações; e Coordenar processos grupais) apresentaram elevada lacuna de competências. Isso confirma achados do 
Relatório do Enade (INEP, 2017b) que aponta fragilidades dos formandos em termos de atuação em processos psicológicos grupais e organizacionais.

Na dimensão Conhecimentos e habilidades de pesquisa científica, a competência em que os formandos em Psicologia estão mais preparados é Apresentar trabalhos e discutir ideias em público, enquanto as competências em que há maior lacuna na formação são Elaborar relatos científicos e Formular questões empíricas de investigação científica. Essas permanecem sendo competências com as quais os(as) psicólogos(as) têm dificuldade ao longo de sua vida profissional, sendo identificadas como pontos que requerem ações de requalificação (Abbad, \& Mourão, 2010).

Por fim, a dimensão Aplicação de habilidades científicas e interação com outros profissionais mostra que os concluintes do curso de Psicologia teriam maior preparo para Desenvolver vínculos interpessoais requeridos na atuação profissional, enquanto as competências de Gerar conhecimento a partir da prática profissional e Realizar intervenções de caráter preventivo figuram como lacunas na formação e requerem desenvolvimento ao longo da vida profissional. Essa demanda por uma educação permanente, aproximando o futuro profissional do(a) psicólogo(a) da realidade social, é apontada por Abdalla, Batista e Batista (2008) como uma demanda para os profissionais da área.

Uma comparação das lacunas percebidas por professores e coordenadores de cursos de Psicologia mostra que, em todas as dimensões, os professores tendem a perceber um grau de lacuna de competências maior que os coordenadores, sendo que os testes $t$ apontaram diferenças significativas entre as médias nas quatro dimen- sões das competências demandadas na formação em Psicologia (Tabela 2). Esses resultados são ainda mais preocupantes, tendo em vista que os coordenadores são os principais responsáveis pela gestão dos cursos. Também foram realizados testes $t$ para comparar diferenças na percepção de docentes de IES públicas e privadas, mas nas quatro dimensões não foram encontradas diferenças significativas em função do tipo de instituição. Esses resultados corroboram com os dados do Relatório do Enade de 2012 (INEP, 2017b), tendo em vista que as médias de desempenho entre formandos provenientes de IES públicas e privadas foram muito similares.

As respostas dos professores e coordenadores às questões abertas complementaram o que eles consideram mais relevante para formação e atuação dos(as) psicólogos(as). Na pergunta sobre outras competências importantes para a formação em Psicologia (Tabela 3), além das 21 previstas pelas diretrizes curriculares do MEC, mereceram destaque: (1) Competências interpessoais $(27,2 \%)$, incluindo ter empatia, habilidades sociais e senso crítico; (2) Conhecimento de teorias, ferramentas e técnicas de intervenção (23,7\%), sendo apontada a necessidade de ampliar os conhecimentos teóricos, as competências específicas e o conhecimento dos processos psicológicos; (3) Compromisso ético (19,3\%), justificado pela natureza ética e de sigilo esperada da profissão; e (4) Compromisso com as políticas públicas $(17,5 \%)$, o que se apoia também no expressivo percentual de psicólogos(as) ligados(as) à rede pública. Outras competências também citadas por vários participantes da pesquisa foram Apropriação da inter- e multidisciplinaridade, Desenvolvimento de práticas científicas

Tabela 2

Testes t com as diferenças entre a percepção de lacunas entre professores e coordenadores.

\begin{tabular}{lccccc}
\hline Dimensões das competências demandadas & Público-alvo & $\mathrm{N}$ & Média & Desvio-padrão & Testes t \\
\hline Intervenção em processos psicológicos & Professores & 72 & 30,4 & 13,8 & $t=5,57 ; g l=109 ;$ \\
individuais & Coordenadores & 39 & 16,7 & 11,5 & $p<0,001$ \\
Conhecimentos e habilidades de pesquisa & Professores & 72 & 32,4 & 16,0 & $t=5,60 ; g l=110 ;$ \\
científica & Coordenadores & 40 & 18,5 & 10,2 & $p<0,001$ \\
Aplicação de habilidades científicas e & Professores & 72 & 30,8 & 15,1 & $t=6,00 ; g l=110 ;$ \\
interação com outros profissionais & Coordenadores & 40 & 15,8 & 11,2 & $p<0,001$ \\
Intervenção em processos psicológicos & Professores & 71 & 35,0 & 14,6 & $t=5,45 ; g l=109 ;$ \\
grupais e organizacionais & Coordenadores & 40 & 20,7 & 12,5 & $p<0,001$ \\
\hline
\end{tabular}

Nota: A amostra total foi de 74 professores e 40 coordenadores. Em cada teste $t$ para amostras independentes foi considerada a amostra máxima para as respostas àquela dimensão, uma vez que se optou por não substituir os dados faltosos pela média. 
Tabela 3

Outras competências importantes para a formação em Psicologia na opinião dos docentes $(\mathrm{n}=114)$.

\begin{tabular}{lcc}
\hline Principais competências citadas & $\mathrm{N}$ & $\%$ \\
\hline Desenvolvimento de competências interpessoais & 31 & 27,2 \\
Conhecimento de teorias, ferramentas e técnicas de intervenção & 27 & 23,7 \\
Compromisso ético & 22 & 19,3 \\
Compromisso com políticas públicas & 20 & 17,5 \\
Apropriação da inter- e multidisciplinaridade & 17 & 14,9 \\
Desenvolvimento de práticas científicas & 16 & 14,0 \\
Desenvolvimento de práticas inovadoras & 13 & 11,4 \\
Gestão da carreira profissional & 13 & 11,4 \\
Conhecimento histórico, econômico e social do Brasil & 12 & 10,5 \\
Preparação e manejo em situações de emergências e catástrofes & 6 & 5,3 \\
Capacidade de atuar na área educacional & 4 & 3,5 \\
Conhecimento em psicopatologia & 3 & 2,6 \\
Desenvolvimento da cultura humanística & 2 & 1,8 \\
\hline
\end{tabular}

Nota.: Os dados da tabela referem-se aos resultados de uma pergunta aberta. A última coluna apresenta o percentual de docentes que citou aquela resposta. Como cada participante poderia citar mais de uma competência, o somatório dos valores ultrapassa $100 \%$. Não foram incluídas competências citadas por apenas um docente.

e inovadoras, Capacidade de atuar em equipe e ser empreendedor, bem como manejo em situações de emergência e catástrofes, capacidade de atuar na área educacional e conhecimento em psicopatologias.

As opiniões dos participantes confirmam a necessidade de que a formação em Psicologia seja repensada em termos da formação de competências, tal como foi sinalizado por autores como Bernardes (2012), Cruz e Schultz (2009), Mourão e Abbad (2016), e Yamamoto e Oliveira (2010).

Quando questionados acerca das principais características do atual mercado de trabalho do(a) psicólogo(a), os docentes destacam três características centrais (Tabela 4): Atuação em políticas públicas (32,5\%), Crescimento e apropriação da inter- e multidisciplinaridade (19,3\%), e Atuação em Psicologia Organizacional e do Trabalho (POT) (14,9\%). As duas primeiras categorias confirmam os achados de Yamamoto e Oliveira (2010) que apontaram o setor público como o de inserção mais expressiva e sistemática dos(as) psicólogos(as) nas últimas décadas, bem como o resultado da pesquisa apresentada pelo Conselho Federal de Psicologia (CFP) (2016), que destaca a atuação prioritária $(74,8 \%)$ nas atividades de educação, saúde e serviços sociais. Vale refletir, contudo, se os(as) psicólogos(as) estão de fato preparados para atuar nos setores sociais (Furtado, 2012).
O aumento da atuação dos(as) psicólogos(as) em equipes multidisciplinares converge com a necessidade de desenvolver habilidades para uma atuação inter-, multi- e transdisciplinar (Ziliotto, Benvenutti, Matiello, \& Peil, 2014), uma vez que os múltiplos saberes e novas dimensões da Psicologia tornaram a profissão mais promissora e ampliaram sua atuação no setor público, com uma proposta formativa de educação interprofissional na perspectiva do trabalho em equipe (Poppe, \& Batista, 2012) e de um paradigma integrador (Ardila, 2011).

Quanto às tendências para a formação do(a) psicólogo(a) nos próximos 10 anos (Tabela 5), destacam-se a maior atuação em políticas públicas $(41,2 \%)$ e a integração entre áreas da Psicologia e outros campos do conhecimento (15,8\%). Pereira e Cortelazzo (2002) já sinalizavam, no início do século XXI, a relevância das atividades de trabalhos comunitários no sentido de preparar os estudantes para atuar em projetos na área social. E Yamamoto (2012) também alertou para a necessidade da proposição de um projeto ético-político para a Psicologia frente a esse novo cenário.

Numa mesma linha, Spink, Bernardes e Menegon (2006) apontaram a importância de potencializar a mudança na graduação, com base na reflexão crítica sobre as experiências na prática da Psicologia no Sistema Único de Saúde (SUS). A atuação nos setores 
Tabela 4

Principais características do atual mercado de trabalho do(a) psicólogo(a) na opinião dos docentes (n=114)

\begin{tabular}{|c|c|c|}
\hline Principais características do mercado de trabalho citadas & $\mathrm{N}$ & $\%$ \\
\hline Atuação em políticas sociais & 37 & 32,5 \\
\hline Apropriação da inter- e multidisciplinaridade & 22 & 19,3 \\
\hline Atuação em Psicologia Organizacional e do Trabalho & 17 & 14,9 \\
\hline Qualificação profissional & 12 & 10,5 \\
\hline Ampliação do mercado de trabalho & 12 & 10,5 \\
\hline Competitividade de mercado & 12 & 10,5 \\
\hline Desvalorização e baixa remuneração profissional & 13 & 11,4 \\
\hline Atuação na área clínica & 10 & 8,8 \\
\hline Atuação na área educacional & 9 & 7,9 \\
\hline Proatividade & 9 & 7,9 \\
\hline Mudanças & 7 & 6,1 \\
\hline Atuação na área jurídica & 7 & 6,1 \\
\hline Criatividade & 6 & 5,3 \\
\hline Saturação da área clínica & 6 & 5,3 \\
\hline Habilidade na comunicação oral e escrita & 4 & 3,5 \\
\hline Atuação profissional com ética & 3 & 2,6 \\
\hline Utilização de práticas com evidências científicas & 3 & 2,6 \\
\hline Exigência de competências generalistas & 3 & 2,6 \\
\hline
\end{tabular}

Nota.: Os dados da tabela referem-se aos resultados de uma pergunta aberta. A última coluna apresenta o percentual de docentes que citou aquela resposta. Como cada participante poderia citar mais de uma característica do atual mercado de trabalho, o somatório dos valores ultrapassa $100 \%$. Não foram incluídas características citadas por apenas um ou dois docentes.

Tabela 5

Principais tendências para a formação nos próximos 10 anos, na opinião dos docentes $(\mathrm{n}=114)$.

\begin{tabular}{lc}
\hline Principais tendências para a formação & N(\%) \\
\hline Aumento da atuação em políticas públicas & $47(41,2)$ \\
Integração entre áreas da Psicologia e outros campos & $18(15,8)$ \\
Crescimento da utilização da pesquisa científica & $11(9,6)$ \\
Ampliação do trabalho com grupos & $11(9,6)$ \\
Formação generalista & $11(9,6)$ \\
Ampliação da atuação em situações de emergências & $8(7,0)$ \\
Fortalecimento da Psicologia jurídica & $7(6,1)$ \\
Desenvolvimento de competências específicas & $7(6,1)$ \\
Maior e melhor articulação entre a teoria e a prática & $7(6,1)$ \\
Ampliação na interface com a neurociência & $6(5,3)$ \\
Ampliação do foco em saúde mental na Psicologia Organizacional e do Trabalho & $5(4,4)$ \\
Revisão das práticas docentes & $4(3,5)$ \\
Ampliação dos currículos a novas demandas & $4(3,5)$ \\
Ampliação da área clínica & $4(3,5)$ \\
Inserção de novas tecnologias & $3(2,6)$ \\
Atuação no trabalho com idosos & $3(2,6)$ \\
Garantia do currículo mínimo para formação & $3(2,6)$ \\
\hline
\end{tabular}

Nota:: Os dados da tabela referem-se aos resultados de uma pergunta aberta. A última coluna apresenta o percentual de docentes que citou aquela resposta. Como cada participante poderia citar mais de uma tendência para a formação nos próximos 10 anos, o somatório dos valores ultrapassa 100\%. Não foram incluídas tendências citadas por apenas um ou dois docentes. 
públicos requer qualificação tanto em termos de formação, quanto na capacidade de empregar em sua prática laboral as competências desenvolvidas.

A pesquisa também contemplou as tendências para o mercado de trabalho do(a) psicólogo(a) para os próximos 10 e 20 anos (Tabela 6). Em ambos os casos, as respostas mais frequentes dos docentes foram a ampliação da atuação em políticas públicas e uma maior habilidade nas relações interpessoais, que confi- gurariam tendências para médio e longo prazo na área. A atuação inter-, multi- e transdisciplinar e a diversidade de locais para atuação também foram apontadas em ambas as previsões, mas com destaque maior para o cenário dos próximos 10 anos. Por um lado, as tendências de maior domínio de abordagens e de atuação mais sistêmica tiveram destaque para médio prazo, mas não foram citadas como tendência para longo prazo. Por outro lado, os docentes enxergam uma pos-

\section{Tabela 6}

Principais tendências para o mercado de trabalho nos próximos 10 e 20 anos, na opinião dos docentes em Psicologia $(n=114)$.

\begin{tabular}{lcc}
\hline Principais tendências para o mercado de trabalho & Nos próximos & Nos próximos \\
20 anos N(\%)
\end{tabular}

Nota.: Os dados da tabela referem-se aos resultados a duas perguntas abertas. As colunas apresentam o valor absoluto e relativo de cada resposta, sendo este último apresentado em percentual e dentro dos parênteses. Como cada participante poderia citar mais de uma tendência para o mercado de trabalho (quer seja para os próximos 10 anos, quer seja para os próximos 20 anos) os somatórios dos percentuais de cada coluna ultrapassam 100\%. Não foram incluídas tendências citadas por apenas um ou dois docentes. 
sibilidade de ampliação do mercado de trabalho para os próximos 20 anos e um retorno à formação generalista, que foram tendências apontadas exclusivamente para o cenário das próximas duas décadas.

Quanto à tendência de maior atuação em políticas públicas, que foi a predominante para o cenário de médio e longo prazo, há evidências históricas de crescimento na área. Tal tendência parte da evolução das políticas sociais no Brasil pós-1985, com o foco na inserção profissional dos(as) psicólogos(as) no campo do bem-estar social, em especial a saúde pública e a assistência social de maneira mais expressiva e sistemática nas últimas décadas (Furtado, 2012; Yamamoto, \& Oliveira, 2010).

As habilidades interpessoais e a atuação inter-, multi-, transdisciplinar contribuem para o aumento dessa tendência porque, segundo, Ziliotto et al. (2014), os múltiplos saberes e novas dimensões tornaram a profissão mais promissora e levaram à sua ampliação no setor público. A proposta formativa para tanto precisa ser de uma educação interprofissional, voltada para o trabalho em equipe, na perspectiva de integralidade e integração (Ardila, 2011; Poppe, \& Batista, 2012).

Por fim, a Tabela 7 apresenta as deficiências na formação em Psicologia na opinião dos docentes pesquisados. As opiniões foram bastante diversas, com destaque para a falta de articulação com o ensino, pesquisa e extensão (34,2\%), falta de articulação entre teoria e prática $(29,8 \%)$, e ênfase excessiva na Psicologia clínica $(21,1 \%)$. Quanto à deficiência sobre a integração entre ensino, pesquisa e extensão, vale destacar que os resultados do Enade apontam que essa articulação está em progresso, pois, em 2006, 32,1\% declaravam ter participado de atividades de pesquisa durante a graduação o que, em 2012, se elevou para

Tabela 7

Principais deficiências da formação em Psicologia, na opinião dos docentes (n = 114).

\begin{tabular}{lcc}
\hline Principais deficiências da formação em Psicologia & $\mathrm{N}$ & $\%$ \\
\hline Falta de articulação com o ensino, pesquisa e extensão & 39 & 34,2 \\
Falta de articulação da teoria com a prática & 34 & 29,8 \\
Ênfase excessiva na Psicologia clínica & 24 & 21,1 \\
Ausência de articulação com as políticas públicas & 16 & 14,0 \\
Formação sem articulação com outros campos do conhecimento & 14 & 12,3 \\
Baixa qualificação dos docentes & 12 & 10,5 \\
Fragmentação e superficialidade teórica & 11 & 9,6 \\
Ausência de planejamento e visão empreendedora na formação & 10 & 8,8 \\
Desconexão teórica com a realidade brasileira & 9 & 7,9 \\
Ausência de habilidades sociais e empatia & 8 & 7,0 \\
Carência de estágios em diversas áreas & 8 & 7,0 \\
Falta de atenção a uma formação ética & 7 & 6,1 \\
Falta de preparo para diagnóstico de grupos e organizações & 7 & 6,1 \\
Dificuldade em elaboração de pareceres e comunicações científicas & 5 & 4,4 \\
Excesso de ênfase em psicanálise & 5 & 4,4 \\
Deficiências na formação básica dos alunos ingressantes & 5 & 4,4 \\
Baixo engajamento e coesão com profissionais e conselho de classe & 5 & 4,4 \\
Ênfase na formação generalista & 4 & 3,5 \\
Falta de oferta de psicoterapia para os alunos & 4 & 3,5 \\
Escassez de material psicométrico traduzido e validado & 3 & 2,6 \\
Ausência de currículo mínimo por região & 3 & 2,6 \\
Clientelismo & 3 & 2,6 \\
\hline
\end{tabular}

Nota:: Os dados da tabela referem-se aos resultados de uma pergunta aberta. A última coluna apresenta o percentual de docentes que citou aquela resposta. Como cada participante poderia citar mais de uma deficiência da formação em Psicologia, o somatório dos valores ultrapassa $100 \%$. Não foram incluídas tendências citadas por apenas um ou dois docentes. 
38,2\%. Já a participação em atividades de extensão, partiu de um patamar de 22,5\% em 2006 para $49,6 \%$ em 2012 (INEP, 2017b).

Mas, apesar desse avanço, é preciso focalizar no desenvolvimento de competências científicas, uma vez que, na opinião dos docentes, essa é uma das maiores fragilidades daqueles que se formam na área. Se a Psicologia for entendida e ensinada como ciência (Cassepp-Borges, 2013; Ziliotto et al., 2014) e com uma preocupação com a prática, a tendência será aumentar a articulação do tripé: ensino, pesquisa e extensão (Souza et al., 2011). Assim, a graduação em Psicologia deve pressupor e assegurar uma formação científica sólida para promover a superação da dissociação entre teoria e prática, relacionando a capacidade de conhecimento do contexto social e científico (Matos, 2000).

\section{Considerações finais}

A profissão de psicólogo(a) cresceu desde as últimas décadas, com aumento no número de formandos e crescimento da demanda no setor público-social. Apesar desse progresso, a formação na área ainda apresenta muitas lacunas de competências e desafios para os próximos anos. As opiniões dos docentes sejam eles coordenadores de curso ou não - mostram preocupação com a área e um conjunto de deficiências que precisa ser enfrentado como parte de um processo coletivo de repensar a profissão. Os resultados apontam maior carência nas competências relativas a Formular questões empíricas de investigação científica; Elaborar relatos científicos; e Elaborar pareceres técnicos, laudos e comunicações profissionais.

Chama a atenção os poucos apontamentos feitos pelos docentes sobre algumas discussões importantes da área, como as competências para o ensino da Psicologia - as licenciaturas e os estágios docentes, bem como sobre as competências gerais das DCNs, que são vinculadas e oriundas dos cursos da área da saúde. A Psicologia não pode ser concebida como uma ciência exclusivamente da área da saúde, pois tal concepção desconsidera a complexidade e diversidade das aplicações da Psicologia, que se caracteriza por ser uma área múltipla e plural. É preciso considerar a Psicologia como, simultaneamente, uma ciência humana, uma ciência da vida psíquica, e uma ciência social.

Os resultados também apontam uma diferença significativa na percepção que os docentes têm sobre o domínio de competências dos egressos de instituições de ensino públicas e privadas. Em geral, as médias de percepção de domínio de competências são menores para os concluintes advindos das instituições privadas. Esse resultado gera uma preocupação se considerarmos que as IES particulares são responsáveis por formar o maior quantitativo de psicólogos(as) no Brasil.

Os apontamentos feitos pelos docentes em termos do futuro que visualizam para a formação e para o mercado de trabalho em Psicologia, bem como os resultados obtidos em termos de competências dos alunos concluintes, convidam a uma reflexão sobre a formação na área. A percepção dos coordenadores de curso parece ser excessivamente otimista, quando contrastada com a percepção dos demais docentes e também com os resultados do Enade - que apontam lacunas de competências muito expressivas na formação em Psicologia. Esse possível "excesso de otimismo" dos coordenadores de curso preocupa, uma vez que os gestores necessitam ter uma avaliação mais precisa das deficiências da formação, a fim de envidar os devidos esforços para combatê-las.

Por um lado, é preciso refletir em que medida a pós-graduação vem conseguindo formar docentes que possam atuar com excelência no ensino da Psicologia. Estaria o foco dos cursos de pós-graduação voltando-se excessivamente para as competências de pesquisa em detrimento das competências docentes? Por outro lado, também é preciso questionar em que medida as novas DCNs, provenientes da Resolução do MEC de 2011, estão conseguindo promover a melhoria que se esperava para a formação em Psicologia. A despeito de terem trazido alguns avanços importantes (ao menos duas ênfases em cada curso de Psicologia e um aumento das atividades práticas desde o início da graduação), as novas DCNs estão permitindo a formação consistente e plural que se espera para os(as) psicólogos(as)?

O fato é que os achados dessa pesquisa - em consonância com os resultados das últimas edições do Enade - apontam para um cenário preocupante sobre a formação em Psicologia. Mas é preciso cuidado ao analisar tais resultados, evitando generalizações, pois a amostra de docentes pesquisados foi reduzida. E embora tenham sido ouvidos docentes das cinco regiões brasileiras, o estudo também tem como limitação o fato de ter uma sub-representação das regiões Norte e Centro-Oeste. Sugere-se, então, que novas pesquisas ampliem a amostra e focalizem nos diferentes contextos das regiões brasileiras, além de ampliar também o público-alvo da pesquisa, pois, além dos docentes, seria importante ouvir os discen- 
tes, os profissionais da área e mesmo membros da sociedade que tenham contato com psicólogos(as) e possam avaliar a sua atuação.

A despeito dessas limitações, o estudo traz importantes reflexões para os estudantes, docentes, psicólogos(as) e demais interessados no campo da formação em Psicologia. Repensar o projeto político pedagógico dos cursos, ampliar o foco na competência social e desenvolver estratégias que permitam articular as atividades de pesquisa, ensino e extensão são recomen- dações que decorrem dos resultados desta pesquisa. Também há uma indicação para uma preparação para o trabalho multidisciplinar e interdisciplinar, considerando que cresce a demanda por este tipo de atuação dos(as) psicólogos(as), bem como o desenvolvimento de estratégias pedagógicas que permitam associar o conhecimento teórico à prática, a fim de construir um saber fazer reflexivo e responsável, que possa atender às demandas da sociedade em termos dos trabalhos esperados dos profissionais de Psicologia.

\section{Referências}

Abbad, G. S., \& Borges-Andrade, J. E. (2014). Aprendizagem humana em organizações de trabalho. In J. C. Zanelli, J. E. Borges-Andrade, J. E., \& A.V.B. Bastos (Orgs.). Psicologia, organizações e trabalho no Brasil (pp. 237-275). Porto Alegre, RS: Artmed.

Abbad, G. S., \& Mourão, L. (2010). Competências profissionais e estratégias de qualificação e requalificação. In A. V. B. Bastos, \& S. M. G. Gondim (Eds.). O trabalho do psicólogo no Brasil (pp. 380-401). Porto Alegre, RS: Artmed.

Abdalla, I. G., Batista, S. H., \& Batista, N. A. (2008). Desafios do ensino de Psicologia clínica em cursos de Psicologia. Psicologia: Ciência e Profissão, 28(4), 806-819. https://doi.org/10.1590/S1414-98932008000400012

Antunes, M. A. M. (2012). Psicologia no Brasil: Um ensaio sobre suas contradições. Psicologia Ciência e Profissão, 32(num esp.), 44-65. https://doi.org/10.1590/S1414-98932012000500005

Ardila, R. (2011). A psicologia no futuro: Os psicólogos mais destacados no mundo falam sobre o futuro de sua disciplina. São Paulo SP: Vetor.

Bastos, A. V. B., Gondim, S. M. G., \& Borges-Andrade, J. E. (2010). As mudanças no exercício profissional da psicologia no Brasil. O que se alterou nas duas últimas décadas e o que se vislumbrou a partir de agora? In A.V. B. Bastos, \& S. M. G. Gondim (Orgs.). O trabalho do psicólogo no Brasil (pp. 419-444). Porto Alegre, RS: Artmed.

Bastos, A. V. B., Gondim, S. M. G., Souza, J. A. J., \& Souza, M. P. R. (2011). Formação básica e profissional do psicólogo: Uma análise do desempenho das IES no Enade. Avaliação Psicológica, 10(3), 313-347.

Bernardes, J. S. (2004). O debate atual sobre a formação em Psicologia no Brasil: Permanências, rupturas e cooptações nas políticas educacionais (Tese de Doutorado). Universidade Católica de São Paulo, São Paulo, SP, Brasil.

Bernardes,J.S.A. (2012). Formação em Psicologia após50 anos do Primeiro Currículo Nacional da Psicologia: Alguns desafios atuais. Psicologia: Ciência e Profissão, 32(num. esp.), 216-231. https://doi.org/10.1590/S1414-98932012000500016

Brasileiro, T. S. A., \& Souza, M. P. R. (2010). Psicologia, diretrizes curriculares e processos educativos na Amazônia: Um estudo na formação de psicólogos. Revista Semestral da Associação Brasileira de Psicologia Escolar e Educacional, 14(1), 105-120. https://doi.org/10.1590/S1413-85572010000100012

Cassep-Borges, V. (2013). Desafios para o futuro da Psicologia: Contribuições da psicologia na construção do conhecimento no século XXI. Psicologia: Ciência e Profissão, 33(num. esp.), 14-23.

Conselho Federal de Psicologia - CFP. (2016). Levantamento de informações sobre a inserção dos psicólogos no mercado de trabalho brasileiro. Brasília, DF: Conselho Federal de Psicologia.

Costa, J. P., Costa, A. L. F., Lima, F. C., Seixas, P. S., Pessanha, V. C., \& Yamamoto, O. H. (2012). A produção científica sobre a formação de psicólogos no Brasil. Psicologia em Pesquisa, 6(2), 130-138.https://doi.org/10.5327/Z1982-12472012000200006

Cruz, R. M., \& Schultz, V. (2009). Avaliação de competências profissionais e formação de psicólogos. Arquivos Brasileiros de Psicologia, 61(3), 117-127.

Furtado, O. (2012). 50 anos de Psicologia no Brasil: A construção social de uma profissão. Psicologia: Ciência e Profissão, 32(num. esp.), 66-85. https://doi.org/10.1590/S1414-98932012000500006

Instituto Nacional de Estudos e Pesquisas Educacionais Anísio Teixeira - INEP (2017a). Sinopse da Educação Superior. Recuperado de http://portal.inep.gov.br/web/guest/sinopses-estatisticas-da-educacao-superior 
Instituto Nacional de Estudos e Pesquisas Educacionais Anísio Teixeira - INEP. (2017b). Relatório do Exame Nacional de Desempenho de Estudantes - Enade. Curso de Psicologia, 2006, 2009, 2012. Recuperado de http://portal. inep.gov.br/relatorios

Lisboa, F. S., \& Barbosa A. J. G. (2009). Formação em Psicologia no Brasil: Um perfil dos cursos de graduação. Psicologia Ciência e Profissão, 29(4), 718-737. https://doi.org/10.1590/S1414-98932009000400006

Matos, M. A. (2000). Definição de diretrizes em uma estruturação curricular em Psicologia e o estágio de formação profissional. Psicologia Informação, 4, 11-24.

Mourão, L., \& Abbad, G. (2016). As lacunas de competências na formação em Psicologia e os riscos para a atuação profissional. In A. B. Soares, L. Mourão, \& M. P. E. Mota (Orgs.). O estudante universitário brasileiro: características cognitivas, habilidades relacionais e transição para o mercado de trabalho (pp. 329-345). Curitiba, PR: Appris.

Pereira, F. M., \& Pereira Neto, A. (2003). O psicólogo no Brasil: notas sobre seu processo de profissionalização. Psicologia em Estudo, 8(2), 19-27. Recuperado de http://www.scielo.br/pdf/pe/v8n2/v8n2a02.

Pereira, E. M. A., \& Cortelazzo, A. L. (2002). Flexibilidade curricular: a experiência em desenvolvimento na Unicamp. Avaliação da Educação Superior, 7(4), 115-128. Recuperado de http://periodicos.uniso.br/ojs/index.php/ avaliacao/article/view/1203

Poppe, A. R. S., \& Batista, S. H. S. S. (2012). Formação em Psicologia no contexto das Diretrizes Curriculares Nacionais: Uma discussão sobre os cenários da prática em saúde. Psicologia: Ciência e Profissão, 32(4), 986-999. https:// doi.org/10.1590/S1414-98932012000400016

Primi, R., Hutz, C. S., \& Silva, M. C. R. (2011). A prova do Enade de Psicologia 2006: Concepção, construção e análise psicométrica da prova. Avaliação Psicológica, 10(3), 271-294.

Resolução No 5, de 15 de março de 2011. (2011). Brasília, DF: Ministério da Educação. Recuperado de http://portal.mec.gov.br/index.php?option=com_docman\&view=download\&alias=7692-rces005-11-pdf\&Itemid=30192

Souza, M. P. R., Bastos, A.V., \& Barbosa, D. R. (2011). Formação básica e profissional do psicólogo: Análise do desempenho dos estudantes no Enade-2006. Avaliação Psicológica, 10(3), 295-312.

Spink, M. J. P., Bernardes, J., \& Menegon, V. S. M. (2006). A Psicologia em diálogo com o SUS: Prática profissional e produção acadêmica. São Paulo, SP: Associação Brasileira de Ensino de Psicologia.

Vilela, A. M. J. (2012). História da Psicologia no Brasil: Uma narrativa por meio de seu ensino. Psicologia: Ciência e Profissão, 32(num esp.), 28-43. https://doi.org/10.1590/S1414-98932012000500004

Yamamoto, O. H. (2012). 50 anos de profissão: responsabilidade social ou projeto ético-político? Psicologia: Ciência e Profissão, 32(num. esp.), 6-17. https://doi.org/10.1590/S1414-98932012000500002

Yamamoto, O. H., \& Oliveira, I. F. (2010). Política social e Psicologia: Uma trajetória de 25 anos. Psicologia: Teoria e Pesquisa, 26, 9-24. https://doi.org/10.1590/S0102-37722010000500002

Ziliotto, D. M., Benvenutti, J., Matiello, M., \& Peil, S. (2014). Concepções e expectativas de estudantes de Psicologia sobre sua futura profissão. Gerais: Revista Interinstitucional de Psicologia, 7(1), 82-92.

\section{Rômulo Travassos}

Docente da Universidade Estadual do Maranhão, São Luís - MA. Brasil.

E-mail: romulo.travassos.silva@gmail.com

\section{Luciana Mourão}

Docente da Universidade Salgado de Oliveira, Niterói - RJ. Brasil.

E-mail: mourao.luciana@gmail.com

Endereço para envio de correspondência:

Rua Santo Inácio de Loiola, 12, apto. 1.207. Olho D’água. CEP: 65067-400.

São Luís - MA. Brasil. 
Recebido 10/12/2016

Reformulado31/01/2018

Aprovado 12/03/2018

Received $12 / 10 / 2016$

Reformulated $01 / 31 / 2018$

Approved 03/12/2018

Recibido 10/12/2016

Reformulado $31 / 01 / 2018$

Aceptado 12/03/2018

Como citar:Travassos, R., \& Mourão, L. (2018). Lacunas de competências de egressos do curso Psicologia na visão dos docentes. Psicologia: Ciência e Profissão, 38(2), 233-248. https://doi.org/10.1590/1982-3703004472016

How to cite: Travassos, R., \& Mourão, L. (2018). Gaps in the skills of graduates of the Psychology course in the professors' view. Psicologia: Ciência e Profissão, 38(2), 233-248. https://doi.org/10.1590/1982-3703004472016

Cómo citar: Travassos, R., \& Mourão, L. (2018). Carencias en las competencias de los egresados del curso de Psicología en la visión de los docentes. Psicologia: Ciência e Profissão, 38(2), 233-248. https://doi.org/10.1590/1982-3703004472016 